\title{
Chronic pulmonary function impairment caused by initial and recurrent pulmonary tuberculosis following treatment
}

\author{
Eva Hnizdo, Tanusha Singh, Gavin Churchyard
}

\begin{abstract}
Background-A study was undertaken to establish the chronic effect of initial and recurrent treated pulmonary tuberculosis on impairment of lung function.

Methods-A total of 27660 black South African gold miners who had reliable pulmonary function tests from January 1995 to August 1996 were retrospectively followed for the incidence of pulmonary tuberculosis to 1970 . The lung function measurements in 1995-6 were related to the number of previous episodes of tuberculosis and to the time that had lapsed from the diagnosis of the last episode of tuberculosis to the lung function test. Miners without tuberculosis or pneumo-
\end{abstract} coniosis served as a comparison group.

Results-There were 2137 miners who had one episode of tuberculosis, 366 who had two, and 96 who had three or more episodes. The average time between the diagnosis of the last episode of tuberculosis and the lung function test was 4.6 years (range one month to 31 years). The loss of lung function was highest within six months of the diagnosis of tuberculosis and stabilised after 12 months when the loss was considered to be chronic. The estimated average chronic deficit in forced expiratory volume in one second $\left(F E V_{1}\right)$ after one, two, and three or more episodes of tuberculosis was $153 \mathrm{ml}, 326 \mathrm{ml}$, and $410 \mathrm{ml}$, respectively. The corresponding deficits for forced vital capacity (FVC) were $96 \mathrm{ml}$, $286 \mathrm{ml}$, and $345 \mathrm{ml}$. The loss of function due to tuberculosis was not biased by the presence of HIV as HIV positive and HIV negative subjects had similar losses. The percentage of subjects with chronic airflow impairment $\left(\mathrm{FEV}_{1}<80 \%\right.$ predicted) was $18.4 \%$ in those with one episode, $27.1 \%$ in those with two, and $35.2 \%$ in those with three or more episodes of tuberculosis. Conclusions-Tuberculosis can cause chronic impairment of lung function which increases incrementally with the number of episodes of tuberculosis. Clearly, prevention of tuberculosis and its effect on lung function is important and can be achieved by early detection and by reduction of the risk of tuberculosis through intervention on risk factors such as HIV, silica dust exposure, silicosis, and socioeconomic factors.

(Thorax 2000;55:32-38)

Keywords: chronic lung function impairment; tuberculosis; silica dust
Several studies have shown that early and partially treated pulmonary tuberculosis can result in airflow obstruction..$^{1-5}$ Studies with longer follow up have shown that a large percentage of cases with treated pulmonary tuberculosis have evidence of permanent airflow obstruction or restrictive impairment. ${ }^{6-8}$ There are no published studies in which the effect of recurrent episodes of treated pulmonary tuberculosis on lung function impairment have been evaluated.

The South African gold mining industry employs over 300000 miners. The risk factors for tuberculosis in gold miners include exposure to silica dust, ${ }^{910}$ silicosis, ${ }^{10-12}$ HIV infection, ${ }^{13}$ socioeconomic factors, and the high risk of tuberculosis in the general South African population. Prior to 1992 the incidence of tuberculosis among working gold miners was stable but high (of the order of 500 smear and/or culture positive cases per 100000 person years). With the advent of HIV the incidence of tuberculosis has been rising consistently and currently is in excess of 2000 cases per 100000 population. ${ }^{14}$ The mines have active and passive case finding programmes and the treatment of tuberculosis follows the World Health Organisation standards. Before 1980 miners who developed pulmonary tuberculosis were not allowed to return to underground mining but, with the introduction of more effective tuberculosis treatment in the early 1980 s, most miners return to underground mining when physically fit to do so.

The main objective of this study was to estimate the effect of treated initial and recurrent tuberculosis on the loss of lung function, especially the chronic effect-that is, the residual deficit in lung function. Specifically, we evaluated (1) the effect of the number of treated tuberculosis episodes on loss of lung function; (2) the effect on loss of lung function of time between the last episode of tuberculosis and the lung function test; (3) the confounding effect of HIV on the loss of lung function due to tuberculosis; and (4) the proportion of subjects with chronic airflow impairment $\left(\mathrm{FEV}_{1}\right.$ $<80 \%$ predicted), according to the number of tuberculosis episodes, in subjects with over 18 months between the last episode of tuberculosis and the lung function test.

\section{Methods}

The study was performed on 27660 black South African gold miners employed by a large gold mining company in whom pulmonary function tests were carried out during the period from January 1995 to August 1996. For
28 July 1999

Accepted for publication

6 September 1999 
these miners the incidence of pulmonary tuberculosis was ascertained retrospectively to 1970.

TUBERCULOSIS CASE DETECTION

The company has an active case finding programme through yearly mass miniature radiographic (MMR) screening. In patients with abnormal radiographs standard size chest radiographs are taken. Three sputum specimens are collected for microscopic examination and culture from those with suspected tuberculosis. All sputum specimens are decontaminated, concentrated, and stained with auramine and Ziehl-Neelsen for microscopic examination and culture on Lowenstein Jensen slants in the hospital laboratory. ${ }^{13}$ Initial identification is done by the local laboratory. From 1994 the Accuprobe Mycobacterium tuberculosis complex culture identification test (Gen-Probe Inc, San Diego, USA), a rapid DNA probe test which uses the technique of nucleic acid hybridisation for the identification of $M$ tuberculosis complex species, has been used to distinguish $M$ tuberculosis from other mycobacteria. The diagnosis of tuberculosis is based on radiological, clinical, and bacteriological results using a validated scoring system, ${ }^{14}$ in accordance with the standard case definition used by the South African national tuberculosis programme. On entry into the employment the miners are interviewed for a previous history of tuberculosis. Of the tuberculosis cases, $0.3 \%$ reported one and $0.001 \%$ reported more than one history of tuberculosis diagnosed before employment in the mines. The company has computerised records of all tuberculosis episodes on all miners from 1970.

HIV TESTING

Patients with suspected tuberculosis are offered voluntary HIV testing with counselling before and after the test. HIV is diagnosed if both the screening (Enzymun-test Anti-HIV 1+2+subtype $\mathrm{O}$, Boehringer Mannheim Immunodiagnostics) and confirmatory (Elisa IM system HIV-1/HIV-2 III Plus, Abbott) diagnostic tests are positive.

DETECTION OF PNEUMOCONIOSIS

Miners whose radiographs are identified as abnormal during yearly MMR screening undergo standard chest radiography. The identity of subjects diagnosed as having silicosis category $1 / 1$ and above according to the ILO category on standard radiographs has been recorded cross sectionally on a computerised database since 1994. These data were used for the present study.

LUNG FUNCTION SCREENING

Lung function screening was introduced in 1994. Spirometric tests are performed routinely on all miners at an initial examination, periodically at three yearly intervals, and on leaving the industry. Maximal forced expiratory manoeuvres are recorded in a computerised database using a Hans Rudolph pneumotachograph (Flowscan, Electromedical
Systems Inc). The system software requires and validates calibration with a three litre syringe. Barometric pressure and temperature are entered via the keyboard for correction of volumes to BTPS. During testing, flow versus volume tracings are displayed. A minimum of three acceptable and reproducible forced expiratory manoeuvres are obtained according to the standards recommended by the American Thoracic Society (ATS). All testing is done by nursing personnel trained in the techniques of performing spirometric tests to ATS standards. Height is measured to the nearest centimetre in stockinged feet. Data computerised for each test include date of test, date of birth, height, weight, the highest forced vital capacity (FVC), highest forced expiratory volume in one second $\left(\mathrm{FEV}_{1}\right)$, and forced expiratory flow at $25-75 \%$ of forced vital capacity $\left(\mathrm{FEV}_{25-75 \%}\right)$. In a reliability study we excluded outliers outside the $99.98 \%$ confidence interval $(C I)$ of the mean $(p<0.0001)$ and established that lung function tests were most reliable from January 1995 to August 1996 (reliability coefficient $\mathrm{G}=0.94$ ). ${ }^{15} \mathrm{Using}$ the data from this period we also estimated predictive lung function curves for miners without a previous history of tuberculosis or pneumoconiosis and found these to be almost identical to those estimated on non-smoking and non-symptomatic black South African men not exposed to dust. ${ }^{16}$

\section{SUBJECT SELECTION}

The 27660 miners comprised all those who had a periodical or exit lung function examination during the reliable testing period (January 1995 to August 1996) $)^{15}$ and whose lung function measurements were within the $99.98 \%$ CI of the mean value. Only one lung function test per miner was used, and the tuberculosis history and pneumoconiosis status prior to the lung function test were established. There were 18754 periodic examinations and 8906 exit examinations. In a preliminary analysis we analysed the two types of examinations separately and established that the results were very similar, and thus the two were combined.

STATISTICAL ANALYSIS

For the descriptive analysis we standardised lung function tests for height of $1.70 \mathrm{~m}$ and tabulated the observed and predicted lung function tests using prediction equations calculated on miners without tuberculosis or pneumoconiosis. The linear regression model was used to estimate the effect of the number of episodes of tuberculosis and the time lapsed from the last episode of tuberculosis on lung function (LF) as follows:

$\mathrm{LF}=\beta_{0}+\beta_{1} \times$ age $+\beta_{2} \times$ height $+\sum_{i=3}^{5} \beta_{1} \times$ episode $_{i}+\sum_{i=6}^{13} \beta_{1} \times$ time $_{i}$

where the dichotomous $(0,1)$ variables episode, $i=3,4,5$ represent one, two, three or more episodes of tuberculosis, respectively, and the dichotomous variables time, $i=6,7, \ldots, 13$ represent lapsed time of 6 months, 7-12 
Table 1 Mean observed (in litres) and percentage predicted values of forced vital capacity (FVC) according to the number of episodes of tuberculosis

\begin{tabular}{|c|c|c|c|c|c|c|c|c|c|c|c|c|}
\hline \multirow{3}{*}{$\begin{array}{l}\text { Age } \\
\text { (years) }\end{array}$} & \multicolumn{12}{|c|}{ Pulmonary tuberculosis } \\
\hline & \multicolumn{3}{|c|}{ No tuberculosis } & \multicolumn{3}{|c|}{1 episode } & \multicolumn{3}{|c|}{2 episodes } & \multicolumn{3}{|c|}{3 episodes } \\
\hline & $n$ & Observed & $\%$ pred & $n$ & Observed & $\%$ pred & $n$ & Observed & $\%$ pred & $n$ & Observed & $\%$ pred \\
\hline $20-24$ & 339 & 4.32 & 98.5 & 1 & 4.77 & 109.2 & & & & & & \\
\hline $25-29$ & 2248 & 4.29 & 99.7 & 38 & 4.10 & 95.5 & 2 & 3.68 & 85.5 & & & \\
\hline $30-34$ & 5416 & 4.22 & 100.1 & 200 & 4.06 & 96.5 & 13 & 3.99 & 94.7 & 2 & 3.89 & 92.5 \\
\hline $35-39$ & 5466 & 4.11 & 100.1 & 355 & 4.01 & 98.0 & 38 & 3.74 & 91.5 & 5 & 2.89 & 70.5 \\
\hline $40-44$ & 4100 & 3.99 & 100.4 & 417 & 3.86 & 97.5 & 75 & 3.71 & 93.6 & 17 & 3.47 & 87.6 \\
\hline $45-49$ & 2906 & 3.84 & 100.7 & 444 & 3.72 & 97.6 & 104 & 3.49 & 91.8 & 36 & 3.38 & 88.8 \\
\hline $50-54$ & 1870 & 3.68 & 101.1 & 367 & 3.54 & 97.1 & 64 & 3.39 & 93.2 & 18 & 3.23 & 88.6 \\
\hline $55-60$ & 1059 & 3.51 & 101.3 & 246 & 3.40 & 98.2 & 58 & 3.12 & 89.3 & 14 & 3.17 & 91.4 \\
\hline $60>$ & 308 & 3.34 & 102.0 & 69 & 3.17 & 96.3 & 12 & 3.08 & 93.8 & 4 & 3.27 & 100.5 \\
\hline Total & 23712 & & & 2137 & & & 366 & & & 96 & & \\
\hline
\end{tabular}

months, $13-18$ months, $19-24$ months, 1-2.9 years, 3-3.9 years, 4-4.9 years, and 6 or more years, respectively. For example, for a person with two episodes of tuberculosis and a time lapse of 7-12 months, the variables episode ${ }_{4}=$ 1 and time $e_{7}=1$ while all the other dichotomous variables are equal to zero.

To establish whether HIV is a confounding factor we estimated the effect of tuberculosis episodes in HIV positive and HIV negative subjects. A comparison group used throughout the analysis comprised subjects who did not have a history of tuberculosis or pneumoconiosis. The percentage of subjects with chronic airflow impairment, defined as $\mathrm{FEV}_{1}<80 \%$ predicted, ${ }^{17}$ was established in subjects with a time lapse of more than 18 months - that is, the time when the loss of lung function due to tuberculosis was found to stabilise.

\section{Results}

Of the 27660 miners, 23712 had neither pneumoconiosis nor tuberculosis, 2599 had a history of tuberculosis, and 1349 miners had pneumoconiosis of whom 185 had tuberculosis also. Of the 2599 miners with tuberculosis only, 2137 had one episode, 366 had two episodes, 79 had three episodes, and 17 had four or more episodes. Tables 1 and 2 show the observed and percentage predicted mean values for height adjusted FVC and $\mathrm{FEV}_{1}$ according to the number of episodes of tuberculosis for five year age categories for subjects who did not have radiological changes for pneumoconiosis. A consistent decrease with episodes of tuberculosis is apparent for all age categories.
Table 3 shows the age and height adjusted regression coefficients $\beta$ and standard errors (SE) for each of the lung function tests (FVC, $\mathrm{FEV}_{1}, \mathrm{FEV}_{1} \%$ and $\left.\mathrm{FEF}_{25-75 \%}\right)$. The regression coefficients represent the decrease in lung function in litres in subjects with increasing number of tuberculosis episodes, in subjects with pneumoconiosis and any number of tuberculosis episodes, and in subjects with pneumoconiosis only compared with subjects who did not have tuberculosis or pneumoconiosis (the baseline group). For example, the

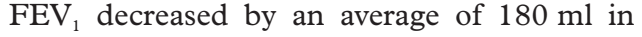
those with one episode of tuberculosis, by $362 \mathrm{ml}$ in those with two episodes, by $462 \mathrm{ml}$ in those with three episodes, and by $964 \mathrm{ml}$ in those with four or more episodes. Subjects with pneumoconiosis and a recorded history of tuberculosis had a decrease of $384 \mathrm{ml}$ while those with pneumoconiosis only had a decrease of $215 \mathrm{ml}$. The prediction equations for the baseline group were: FVC $=-2.901-0.025 \times$ age $+4.655 \times$ height; $\mathrm{FEV}_{1}=-1.654-0.030 \times$ age $+3.665 \times$ height (age in years and height in metres).

Table 4 shows the age and height adjusted regression coefficients and standard errors for the number of tuberculosis episodes (three and more episodes were combined) and the time between the diagnosis of the last episode of tuberculosis and the lung function test. The coefficients allow us to calculate the loss due to specific numbers of episodes and time elapsed. For example, the loss of $\mathrm{FEV}_{1}$ in subjects with one episode of tuberculosis and a time lapse of six months is $[0.729+(-1.055)] \times 1000=$ $-326 \mathrm{ml}$, with a time lapse of 12 months it is

Table 2 Mean observed (in litres) and percentage predicted values of forced expiratory volume in one second (FEV) according to the number of episodes of tuberculosis

\begin{tabular}{|c|c|c|c|c|c|c|c|c|c|c|c|c|}
\hline \multirow{3}{*}{$\begin{array}{l}\text { Age } \\
\text { (years) }\end{array}$} & \multicolumn{12}{|c|}{ Pulmonary tuberculosis } \\
\hline & \multicolumn{3}{|c|}{ No tuberculosis } & \multicolumn{3}{|c|}{1 episode } & \multicolumn{3}{|c|}{2 episodes } & \multicolumn{3}{|c|}{3 episodes } \\
\hline & $n$ & Observed & $\%$ pred & $n$ & Observed & $\%$ pred & $n$ & Observed & $\%$ pred & $n$ & Observed & $\%$ pred \\
\hline $20-24$ & 339 & 3.79 & 97.6 & 1 & 4.21 & 109.2 & & & & & & \\
\hline $25-29$ & 2248 & 3.73 & 99.6 & 38 & 3.59 & 96.4 & 2 & 3.08 & 82.6 & & & \\
\hline $30-34$ & 5416 & 3.61 & 100.1 & 200 & 3.43 & 95.5 & 13 & 3.18 & 88.6 & 2 & 3.74 & 104.3 \\
\hline 35-39 & 5466 & 3.45 & 100.2 & 355 & 3.31 & 96.5 & 38 & 3.09 & 90.3 & 5 & 2.36 & 68.5 \\
\hline $40-44$ & 4100 & 3.30 & 100.7 & 417 & 3.12 & 95.4 & 75 & 3.02 & 92.3 & 17 & 2.71 & 83.0 \\
\hline $45-49$ & 2906 & 3.16 & 101.8 & 444 & 2.95 & 95.4 & 104 & 2.75 & 89.0 & 36 & 2.59 & 83.9 \\
\hline $50-54$ & 1870 & 2.99 & 102.3 & 367 & 2.77 & 95.1 & 64 & 2.63 & 90.0 & 18 & 2.46 & 84.0 \\
\hline $55-60$ & 1059 & 2.83 & 103.3 & 246 & 2.60 & 95.0 & 58 & 2.44 & 88.1 & 14 & 2.25 & 82.2 \\
\hline $60>$ & 308 & 2.65 & 103.9 & 69 & 2.46 & 95.6 & 12 & 2.29 & 89.4 & 4 & 2.38 & 93.5 \\
\hline Total & 23712 & & & 2137 & & & 366 & & & 96 & & \\
\hline
\end{tabular}


Table 3 Age and height adjusted regression coefficients $\beta$ and standard errors (SE) for lung function tests for 27660 miners

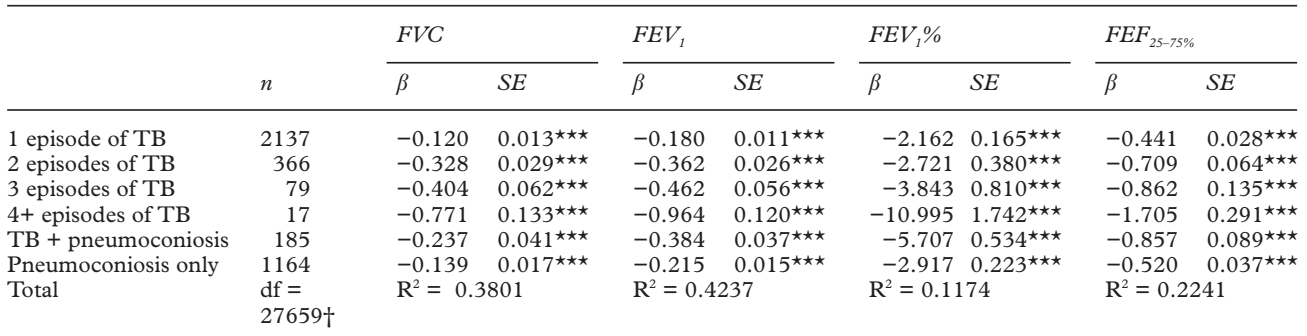

$\mathrm{TB}=$ tuberculosis $; \mathrm{FEV}_{1}=$ forced expiratory volume in one second; $\mathrm{FVC}=$ forced vital capacity; $\mathrm{FEF}_{25-75 \%}=$ forced expiratory flow at $25-75 \%$ of forced vital capacity.

$\star \star \star \mathrm{p}<0.001$.

†There were 23712 additional miners who did not have TB who were used as a comparison group in the regression model.

$[0.729+(-0.975)] \times 1000=-247 \mathrm{ml}$, with 18 months it is $[0.729+(-0.868)] \times 1000=$ $-139 \mathrm{ml}$, and with 24 months it is [0.729+ $(-0.865)] \times 1000=-136 \mathrm{ml}$. For subjects with three and more episodes the corresponding losses are $-583 \mathrm{ml},-503 \mathrm{ml},-396 \mathrm{ml}$, and $-393 \mathrm{ml}$. The data show that the loss of lung function is highest in the first six months and stabilises at 13-18 months.

Table 5 shows the age and height adjusted regression coefficients and standard errors for the number of episodes of tuberculosis for subjects known to be HIV negative $(n=1038)$ and for those known to be HIV positive $(\mathrm{n}=305)$.
There were no apparent major differences between the two groups.

Figure 1 shows the decline in lung function (FVC, $\mathrm{FEV}_{1}$, and $\mathrm{FEV}_{1} \%$ ) with age for subjects without tuberculosis and pneumoconiosis, according to number of tuberculosis episodes, estimated cross sectionally. The plotted curves were estimated individually for each group and indicate that, in addition to the average loss due to the tuberculosis episodes, subjects with tuberculosis also have a steeper decline with age.

Figure 2 shows the percentage of subjects whose percentage predicted $\mathrm{FEV}_{1}$ was below

Table 4 Age and height adjusted regression coefficients $\beta$ and standard errors (SE) for the number of TB episodes and the time elapsed from last TB episode to lung function test for 26311 miners who did not have pneumoconiosis, and loss of lung function after one episode and specific lapsed time

\begin{tabular}{|c|c|c|c|c|c|c|c|c|c|c|}
\hline & \multirow[b]{2}{*}{$n$} & \multicolumn{3}{|l|}{$F V C$} & \multicolumn{3}{|l|}{$F E V_{1}$} & \multicolumn{3}{|l|}{$F E V_{1} \%$} \\
\hline & & $\beta$ & $S E$ & Loss $\neq$ & $\beta$ & $S E$ & Loss $\neq$ & $\beta$ & $S E$ & Loss $\neq$ \\
\hline 1 episode of TB & 2137 & 0.578 & $0.134^{\star \star \star}$ & & 0.729 & $0.120^{\star \star \star}$ & & 9.016 & $1.726^{\star \star \star}$ & \\
\hline 2 episodes of TB & 366 & 0.388 & $0.136^{\star \star}$ & & 0.556 & $0.122^{\star \star \star}$ & & 8.307 & $1.753^{\star \star \star}$ & \\
\hline $3+$ episodes of TB & 96 & 0.329 & $0.146^{\star}$ & & 0.472 & $0.131^{\star \star \star}$ & & 7.211 & $1.885^{\star \star \star}$ & \\
\hline \multicolumn{11}{|c|}{ Catogorised time elapsed from last TB episode to lung function test } \\
\hline $1-6$ months & 216 & -0.883 & $0.134^{\star \star \star}$ & -0.305 & -1.055 & $0.121^{\star \star \star}$ & -0.326 & -10.874 & $1.735^{\star \star \star}$ & -1.858 \\
\hline $7-12$ months & 259 & -0.791 & $0.137^{\star \star \star}$ & -0.213 & -0.975 & $0.123^{\star \star \star}$ & -0.246 & -10.963 & $1.766^{\star \star \star}$ & -1.947 \\
\hline 13-18 months & 198 & -0.666 & $0.138^{\star \star \star}$ & -0.088 & -0.868 & $0.124^{\star \star \star}$ & -0.139 & -10.827 & $1.778^{\star \star \star}$ & -1.811 \\
\hline 19-24 months & 179 & -0.636 & $0.138^{\star \star \star}$ & -0.058 & -0.865 & $0.124^{\star \star \star}$ & -0.136 & -11.396 & $1.784^{\star \star \star}$ & -2.380 \\
\hline $25-36$ months & 291 & -0.653 & $0.136^{\star \star \star}$ & -0.075 & -0.882 & $0.123^{\star \star \star}$ & -0.153 & -11.405 & $1.761^{\star \star \star}$ & -2.389 \\
\hline $37-48$ months & 268 & -0.688 & $0.137^{\star \star \star}$ & -0.110 & -0.898 & $0.123^{\star \star \star}$ & -0.169 & -11.092 & $1.765^{\star \star \star}$ & -2.076 \\
\hline 49-60 months & 216 & -0.733 & $0.139^{\star \star \star}$ & -0.155 & -0.886 & $0.125^{\star \star \star}$ & -0.157 & -9.669 & $1.790^{\star \star \star}$ & -0.653 \\
\hline $61-375$ months & 972 & -0.665 & $0.135^{\star \star \star}$ & -0.087 & -0.895 & $0.121^{\star \star \star \star}$ & -0.166 & -11.597 & $1.741^{\star \star \star}$ & -2.581 \\
\hline Total & $\begin{array}{l}\mathrm{df}= \\
26309 \dagger\end{array}$ & \multicolumn{3}{|c|}{$\mathrm{R}^{2}=0.3711$} & \multicolumn{3}{|c|}{$\mathrm{R}^{2}=0.4075$} & \multicolumn{2}{|c|}{$\mathrm{R}^{2}=0.1011$} & \\
\hline
\end{tabular}

$\mathrm{TB}=$ tuberculosis $; \mathrm{FEV}_{1}=$ forced expiratory volume in one second $; \mathrm{FVC}=$ forced vital capacity.

${ }^{\star} \mathrm{p}<0.05 ;{ }^{\star \star} \mathrm{p}<0.01 ;{ }^{\star \star \star} \mathrm{p}<00.001$.

†There were 23710 miners who did not have TB, who were used as a comparison group in the regression model.

$\neq$ Loss of lung function after one episode of TB and specific lapsed time from the last episode of TB.

Table 5 Age and height adjusted regression coefficients $\beta$ and standard errors (SE) for the number of TB episodes and 25055 subjects known to be HIV positive or HIV negative

\begin{tabular}{|c|c|c|c|c|c|c|c|c|c|}
\hline & \multirow[b]{2}{*}{$n$} & \multicolumn{2}{|l|}{$F V C$} & \multicolumn{2}{|l|}{$F E V_{1}$} & \multicolumn{2}{|l|}{$F E V_{1} \%$} & \multicolumn{2}{|l|}{$F E F_{25-75 \%}$} \\
\hline & & $\beta$ & $S E$ & $\beta$ & $S E$ & $\beta$ & $S E$ & $\beta$ & $S E$ \\
\hline \multicolumn{10}{|l|}{ HIV negative } \\
\hline 1 episode of TB & 747 & -0.172 & $0.020^{\star \star \star}$ & -0.233 & $0.018^{\star \star \star}$ & -2.439 & $0.260^{\star \star \star}$ & -0.523 & $0.045^{\star \star \star}$ \\
\hline 2 episodes of TB & 218 & -0.332 & $0.037^{\star \star \star}$ & -0.377 & $0.033^{\star \star \star}$ & -3.066 & $0.475^{\star \star \star}$ & -0.769 & $0.082^{\star \star \star}$ \\
\hline $3+$ episodes of TB & 73 & -0.485 & $0.064^{\star \star \star}$ & -0.529 & $0.057^{\star \star \star}$ & -4.084 & $0.814^{\star \star \star}$ & -0.918 & $0.301^{\star \star \star}$ \\
\hline \multicolumn{10}{|l|}{ HIV positive } \\
\hline 1 episode of TB & 234 & -0.162 & $0.036^{\star \star \star}$ & -0.210 & $0.032^{\star \star \star}$ & -1.586 & $0.457^{\star \star \star}$ & -0.382 & $0.079^{\star \star \star}$ \\
\hline 2 episodes of TB & 55 & -0.433 & $0.073^{\star \star \star}$ & -0.479 & $0.066^{\star \star \star}$ & -3.273 & $0.939^{\star \star \star}$ & -0.863 & $0.163^{\star \star \star}$ \\
\hline $3+$ episodes of TB & 16 & -0.500 & $0.136^{\star \star \star}$ & -0.564 & $0.122^{\star \star \star}$ & -4.520 & $1.739^{\star \star}$ & -0.974 & $0.301^{\star \star}$ \\
\hline Total & $\begin{array}{l}\mathrm{df}= \\
25053 \dagger\end{array}$ & \multicolumn{2}{|c|}{$\mathrm{R}^{2}=0.3511$} & \multicolumn{2}{|c|}{$\mathrm{R}^{2}=0.3784$} & \multicolumn{2}{|c|}{$\mathrm{R}^{2}=0.1095$} & \multicolumn{2}{|c|}{$\mathrm{R}^{2}=0.2447$} \\
\hline
\end{tabular}

$\mathrm{TB}=$ tuberculosis $; \mathrm{FEV}_{1}=$ forced expiratory volume in one second; $\mathrm{FVC}=$ forced vital capacity; $\mathrm{FEF}_{25-75 \%}=$ forced expiratory flow at $25-75 \%$ of forced vital capacity.

${ }^{\star \star} \mathrm{p}<0.01 ;{ }^{\star \star \star} \mathrm{p}<0.001$.

†There were 23712 miners who did not have TB who were used as a comparison group in the regression model. 

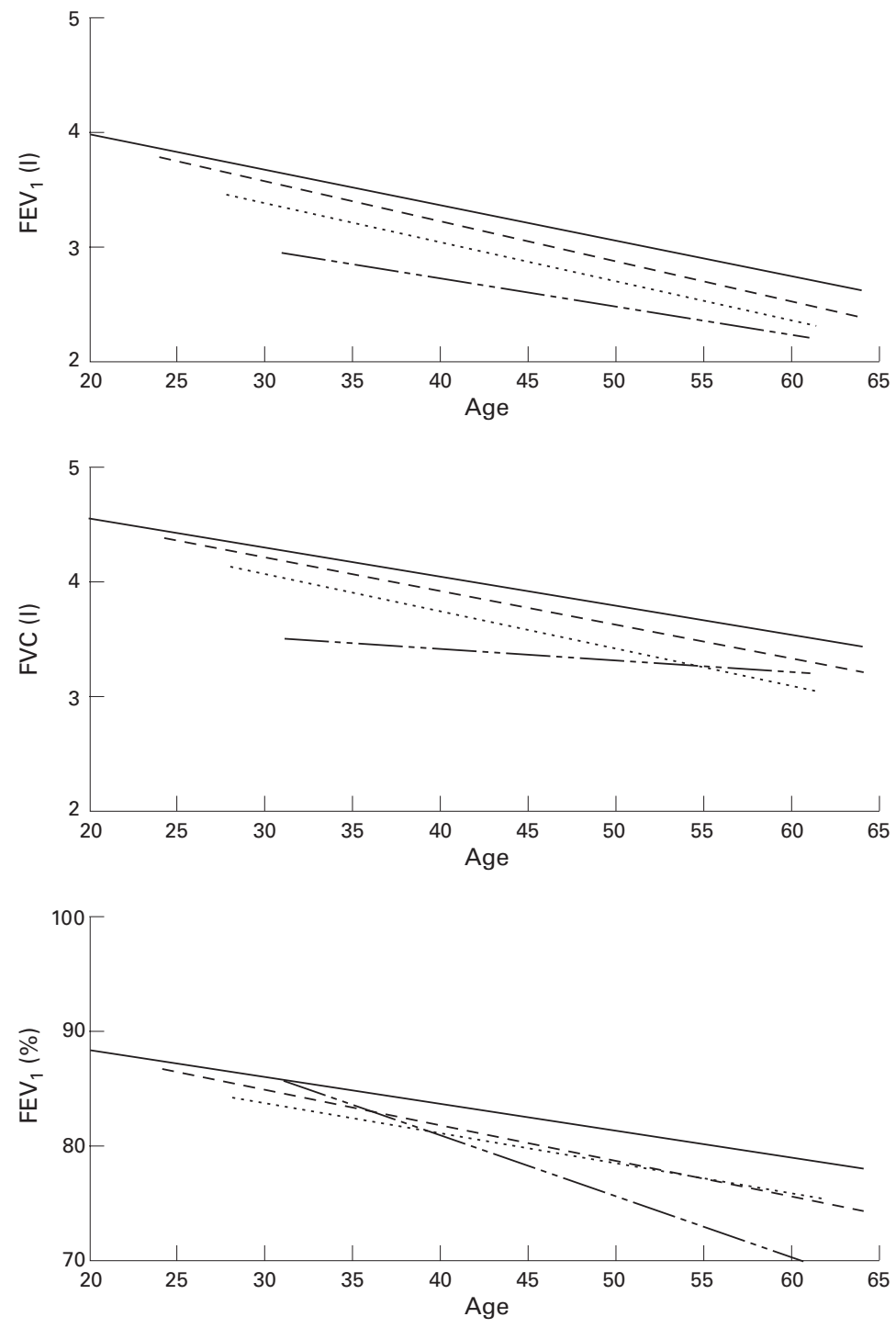

Figure 1 Decline in lung function with age for miners with one (--- -), two (....), and three and more (_. - _ episodes of tuberculosis.

$80 \%$ for miners without tuberculosis or pneumoconiosis, and for those with one, two, and three or more episodes of tuberculosis. To estimate the chronic loss - that is, the residual deficit in lung function-subjects with a time lapse of less than 18 months were excluded from this calculation.

\section{Discussion}

Several studies have observed that early and partially treated tuberculosis results in airways obstruction. ${ }^{1-5}$ Only a few studies with a follow up of more than 18 months have been performed. In one study $68 \%$ of 71 subjects had evidence of airways obstruction after 9-192 months (average 5.6 years) of follow up from diagnosis of tuberculosis. ${ }^{6}$ Impairment of airflow was related to the extent of tuberculosis determined radiologically and to the amount of sputum produced at the end of follow up, which also correlated with the extent of the disease. ${ }^{6}$ In another study obstructive changes were found to be most common after 10 years of follow up and were correlated with the

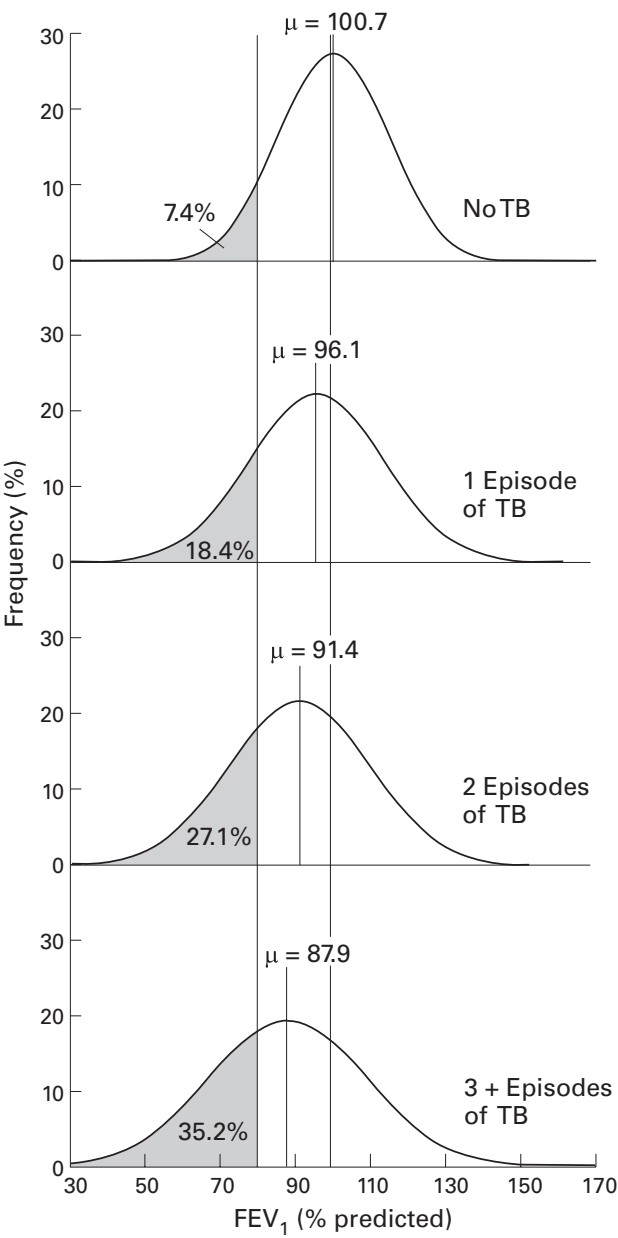

Figure 2 Distribution of percentage predicted forced expiratory volume in one second $(F E V)$ and percentage of subjects below the $80 \%$ predicted value.

extent of residual shadowing on the chest radiographs. ${ }^{7} \mathrm{~A}$ third study observed that, after 15 years of follow up, 40 patients with pulmonary tuberculosis who had obstructive impairment on discharge had a higher estimated yearly decline in vital capacity than those without obstruction $(-54.3 \mathrm{ml} / \mathrm{year}$ versus $-27.7 \mathrm{ml} /$ year) but the decline in $\mathrm{FEV}_{1}$ was only slightly higher. ${ }^{8}$

The residual damage to the lung tissue after completion of tuberculous treatment includes varying degrees of fibrosis, bronchovascular distortion, emphysema, and bronchiectasis. ${ }^{18}$ Increased sputum production was also observed several years after tuberculosis treatment that correlated with the initial extent of tuberculosis on the radiographs. ${ }^{6}$ The present study quantifies the loss of lung function caused by initial and recurrent treated tuberculosis and by specific time lapsed after tuberculosis diagnosis, especially the chronic damage due to tuberculosis episodes in a gold mining population screened and treated for tuberculosis according to WHO guidelines.

Because of exposure to silica dust, the South African gold miners are at an increased risk of developing pulmonary tuberculosis and many miners develop several episodes of 
tuberculosis which are thought to be mainly due to reinfection. As most miners continue to be exposed to silica dust after treatment, it is important to evaluate the impact of recurrent episodes of tuberculosis on loss of lung function in these subjects. The present study evaluated the impact of recurrent episodes of treated tuberculosis on impairment of lung function in 27660 black South African gold miners of whom 2137 had had one episode of tuberculosis, 366 two episodes, 79 three episodes, and 17 four or more episodes of tuberculosis.

The increased number of episodes of tuberculosis corresponded with increasing loss of lung function. This loss was the highest in the first six months after diagnosis of tuberculosis, and became stable in 13-18 months. The estimated decrease in $\mathrm{FEV}_{1}$ in subjects with one episode of tuberculosis was $326 \mathrm{ml}$ after six months, $247 \mathrm{ml}$ after one year, and stabilised at an average residual loss of $153 \mathrm{ml}$ over the total follow up period (table 4); for subjects with two episodes of tuberculosis the temporal loss of $\mathrm{FEV}_{1}$ was $499 \mathrm{ml}$ after six months, $419 \mathrm{ml}$ after 12 months, and stabilised at an average residual loss of $326 \mathrm{ml}$ from 12 months onwards; while for subjects with three episodes of tuberculosis the temporal loss of $\mathrm{FEV}_{1}$ was $583 \mathrm{ml}$ after six months, $503 \mathrm{ml}$ after 12 months, and stabilised at an average residual loss of $410 \mathrm{ml}$.

For FVC the estimated decrease in subjects with one episode of tuberculosis was $305 \mathrm{ml}$ after six months, $213 \mathrm{ml}$ after one year, and stabilised at an average residual loss of $96 \mathrm{ml}$ over the total follow up period (table 4); for subjects with two episodes the temporal loss of FVC was $495 \mathrm{ml}$ after six months, $403 \mathrm{ml}$ after 12 months, and stabilised at an average residual loss of $286 \mathrm{ml}$ from 12 months onwards; and for subjects with three episodes of tuberculosis the temporal loss of FVC was $554 \mathrm{ml}$ after six months, $462 \mathrm{ml}$ after 12 months, and stabilised at an average residual loss of $345 \mathrm{ml}$. However, the loss in $\mathrm{FEV}_{1} \%$ showed a different pattern, suggesting an increase in the obstructive pattern with increasing duration of the follow up period (table 4), especially in subjects with three or more episodes of tuberculosis. This result is in agreement with the previous studies with longer follow up periods which observed an obstructive pattern in patients with tuberculosis. ${ }^{67}$

The presence of HIV infection in many tuberculosis subjects did not bias the estimated effect of tuberculosis on lung function as those who tested HIV positive and HIV negative at the time of the diagnosis of tuberculosis had a similar loss of lung function (table 5). In recent years almost all subjects presenting with tuberculosis are tested for HIV infection. The effect of pneumoconiosis on loss of lung function was similar to that of one episode of tuberculosis.

To determine the percentage of subjects with chronic lung function impairment we calculated the percentage of subjects whose predicted $\mathrm{FEV}_{1}$ was below $80 \%$-namely, $18.4 \%$ in those with one episode of tuberculosis,
$27.1 \%$ in those with two episodes of tuberculosis, and $35.2 \%$ in those with three or more episodes of tuberculosis (fig 2). This result shows that miners with a history of pulmonary tuberculosis need to be carefully monitored for chronic impairment of lung function and that prevention of further episodes of tuberculosis in these miners is of great importance.

Limitations of the study include the lack of adjustment for smoking and exposure to silica dust and the retrospective assessment of tuberculosis history. Tobacco smoking could potentially have biased the estimated effect of tuberculosis on loss of lung function as tobacco smoking was found to be associated with an increased risk of tuberculosis in a cohort of white gold miners, ${ }^{10}$ and smoking is known to increase lung function loss. However, the bias is unlikely to be of substantial importance as black gold miners generally have substantially lower tobacco consumption (5-10 cigarettes per day) than that of the cohort of white miners (20-50 cigarettes per day). ${ }^{19}$ In the absence of data on exposure to silica dust, silicosis has been shown to act as a surrogate variable for the effect of exposure to silica dust on loss of lung function in miners with a relatively low rate of pulmonary tuberculosis ${ }^{20}$ but it is possible that the extent of lung damage due to tuberculosis is potentiated by the silica dust load in the lung. Because of retrospective assessment of tuberculosis, healthy survival effect could have resulted in the underestimation of the effect of tuberculosis on lung function. There is some indication of the presence of this effect in fig 1 . Younger subjects with three episodes of tuberculosis have FVC almost as low as that of older subjects, suggesting that the older subjects could be those with three less damaging episodes of tuberculosis and that older miners with extensive loss of lung function due to three or more episodes of tuberculosis had left the mines.

In conclusion, tuberculosis can cause chronic lung function impairment which increases incrementally with the number of episodes of tuberculosis, affecting approximately $18 \%$ of subjects with one episode, $27 \%$ of subjects with two episodes, and $35 \%$ of subjects with three episodes of tuberculosis. Clearly, prevention of chronic lung function impairment caused by tuberculosis in gold miners would be accomplished by preventing tuberculosis through intervention on risk factors such as HIV, silica dust exposure, silicosis, and socioeconomic factors, and by detection of the tuberculosis episodes at an early stage.

The authors thank the Anglogold Health Services, which covers the workforce of Freegold mines in Welkom in South Africa, for allowing them to use their lung function, pulmonary tuberculosis and radiological data and acknowledge valuable comments from Dr Jill Murray and Professor A Solomon. The study received funding from the Safety in Mines Research Advisory Committee.

1 Snider GL, Doctor L, Demas TA, et al. Obstructive airways disease in patients with treated pulmonary tuberculosis. $A m$ disease in patients with treated pulm
Rev Respir Dis 1971;103:625-40.

2 Birath G, Caro J, Malmbere R, et al. Airways obstruction in pulmonary tuberculosis. Scand F Respir Dis 1966;47:27-36. 
3 Lancaster JF, Tomashefski JF. Tuberculosis: a cause of emphysema. Am Rev Respir Dis 1963;87:435-7.

4 Simpson DG, Kuschner M, McClement J. Respiratory function in pulmonary tuberculosis. Am Rev Respir Dis 1963;87:1-16.

5 Plit ML, Anderson R, Van Rensburg CEJ, et al. Influence of antimicrobial chemotherapy on spirometric parameters and pro-inflammatory indices in severe pulmonary tuberculosis. Eur Respir f 1998;12:351-6.

6 Willcox PA, Ferguson AD. Chronic obstructive airways disease following treated pulmonary tuberculosis. Respir Med 1989;83:195-8.

7 Krishna K, Bond S, Artvinli M, et al. Pulmonary function in treated tuberculosis; a long term follow-up. Am Rev Respir Dis 1977;115:402.

8 Vargha G. Fifteen year follow-up of lung function on obstructive and non-obstructive pulmonary tuberculosis. Acta Med Hung 1983;40:271-6

Acta Med Hung 1983;40:271-6
9 Kleinschmidt I, Churchyard G. Variation in incidence of tuberculosis in subgroups of South African gold miners. Occup Environ Med 1997;54:636-41.

10 Hnizdo E, Murray J. Risk of pulmonary tuberculosis relative to silicosis and exposure to silica dust in South African gold to silicosis and exposure to silica dust in South
miners. Occup Environ Med 1998;55:496-502.

11 Cowie RL. The epidemiology of tuberculosis in gold miners with silicosis. Am $\mathcal{F}$ Respir Crit Care Med 1994;150:1460-2.
12 Murray J, Kielkowski D, Reid P. Occupational disease trends in black South African gold miners. Am $\mathcal{F}$ Respir Crit Care Med 1996;153:706-10.

13 Corbett EL, Churchyard GJ, Moyake T, et al. HIV infection, silicosis and mycobacterial disease incidence in South African miners. Int F Tuberc Lung Dis 1998;2:S301.

14 Escreet BC, Langton ME, Cowie RL. Short-course chemotherapy for silicotuberculosis. S Afr Med F 1984; 68:327-30.

15 Hnizdo E, Churchyard G, Barnes D, et al. Assessment of reliability of lung function screening program. Am F Respir Crit Care Med 1999 (in press).

16 Louw SJ, Goldin JG, Joubert G. Spirometry of healthy adult South African men. S Afr Med F 1996;86:814-9.

17 Snedecor GW, Cochran WG. Statistical methods. Iowa: The Iowa State University Press, 1968

18 Jung-Gi Im, Harumi Iton, Kyung Soo Lee, et al. CT-pathology correlation of pulmonary tuberculosis. Crit Rev Diagn Imaging 1995;36:227-85.

19 Cowie RL, Mabena SK. Silicosis, chronic airflow limitation and chronci bronchitis in South African gold miners. Am Rev Respir Dis 1991;143:80- 4.

20 Hnizdo E, Hessel PA, Sluis-Cremer GK. Chronic airflow limitation in South African gold miners. Am Rev Respir Dis 1991;148:1423 